\title{
Building a culture of workplace wellness: Perspectives from Philippine organizations
}

Hechanova, Ma. Regina M.

Ateneo de Manila University, Philippines (rhechanova@ateneo.edu)

Caringal-Go, Jaimee Felice A.

Ateneo de Manila University, Philippines (jfgo@ateneo.edu)

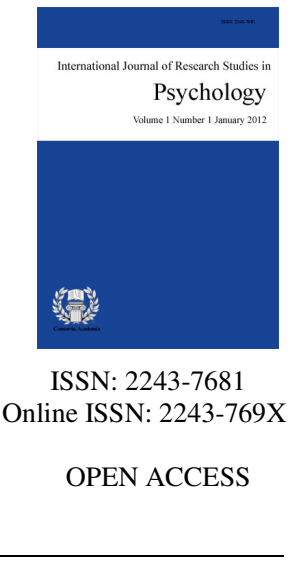

Received: 24 April 2018

Revised: 4 June 2018 DOI: $10.5861 / \mathrm{ijrsp} .2018 .3010$

Accepted: 24 June 2018

\section{Abstract}

This study explored approaches to building a culture of wellness in the workplace from a developing country perspective. Focus group discussions with HR practitioners and health professionals in the Philippines were conducted. Deductive thematic analysis was used to organize the data. Results showed that organizations use a variety of strategies in building workplace wellness, which could be classified using the CREATE framework - Communicate, Role model, Engage employees, Align systems, structures and policies, Train, Evaluate and reinforce. The identified strategies and CREATE framework can be utilized as a guide for organizations planning to implement workplace wellness initiatives in a holistic manner.

Keywords: culture; wellness; developing country; Philippines; workplace 


\section{Building a culture of workplace wellness: Perspectives from Philippine organizations}

\section{Introduction}

Given the amount of time employees spend at work, the workplace is an important setting to promote health. A study in Australia reported that productivity loss due to alcohol use is about \$AUD 3.6 billion annually (Pidd, Roche, \& Fischer, 2015). A study among firefighters reported that a wellness-fitness program prevented $10 \%$ of cardio vascular events (CVE) and resulted in savings of \$1.44M per CVE (Patterson, Smith, \& Hostler, 2016). Company investments in employee health are likewise associated with lower absenteeism, increased job satisfaction, improved productivity and a more positive corporate image (Lee, Blake, \& Lloyd, 2010). Wellness programs have also been found to reduce health care costs and improve productivity among local government offices in the Unites States (Sabharwal, Kiel, \& Hijal-Moghrabi, 2016).

Even as workplace wellness makes good business sense, many organizations do not prioritize occupational health initiatives because of the costs entailed. This is perhaps why, historically, workplace health initiatives have emerged from medium-sized and large organizations (McPeck, Ryan, \& Chapman, 2009). However, in the recent years, there has been increasing interest on workplace wellness strategies even in small businesses (McPeck et al., 2009; Rucker, 2017).

Majority of studies on workplace wellness are also from developed countries and there is an absence of studies from low to middle income countries (LMICs) (Schulte, O’Donnell, Kastner, Schidt, Schafer et al., 2014). However, the World Health Organization (2013) reports that the issue of occupational health and workplace wellness is particularly salient in developing economies that are plagued with poverty, lack of education, poor working conditions, excessive working hours and poor diet. A workplace study in Sri Lanka reports that a large majority of workers are in small-scale industries and face occupational hazards such as manual labor and long hours. In their study, the most commonly cited work-related health problem of workers is muscoskeletal pain (Sureweera, Wijesinghe, Senanayake, Herath, \& Jayalal, 2016).

The vulnerabilities of workers in developing countries are compounded by the lack of resources for health. In the Philippines for example, only 3.3\% of its GDP is spent on healthcare as opposed to what is spent by developed economies such as the United States (17.9\%). Moreover, resources for mental health are scarce. Unlike developed economies such as Canada that has one mental health practitioner for every 7,930 persons, in the Philippines, the ratio of psychiatrists to clients is .41:100,000 (World Health Organization, 2007) and psychologists is 1:100,000 (Hechanova, Waelde, et al., 2015). Although the country has just recently passed a Mental Health bill act supporting mental health services and treatment, the bill has yet to be implemented. Given the lack of resources support from national government, the burden of mental health lies on individuals and employers.

Given the dearth of studies on workplace wellness from developing economies, this study seeks to add to the global literature by describing strategies undertaken in enabling a culture of wellness among Philippine organizations.

\subsection{Workplace wellness}

Workplace wellness is often associated with interventions and programs designed to improve the physical and mental health of employees. To date, much of the research on workplace interventions have been directed towards illnesses such as obesity, cardiovascular diseases, and diabetes (Meng et al., 2017). There is also literature on workplace substance use interventions that seek to decrease stress levels and alcohol consumption (Pidd et al., 2015; Schulte et al., 2014). Numerous studies have also focused on understanding sources of stress in the workplace, and suggesting interventions to help employees effectively manage and cope with stress. 
(Akanji, 2016; Kanene \& Mushungekelwa, 2016; Riley et al., 2016). Examples include short outdoor breaks, mindfulness training, and breathing and relaxation training (Bazarko, Cate, Acozar, \& Kreitzer, 2013; Largo-Wight, Wlyudka, Merten, \& Cuvelier, 2017; Safaria, 2014).

Beyond interventions, however, there is an increasing awareness of the importance of organizational factors that contribute to employee health. More specifically, there is evidence that an organizational culture that supports the psychosocial needs of employees is an important factor in employees' overall wellbeing (Dickson-Swift, Fox, Marshall, Welch, \& Willis, 2014).

\subsection{Culture building}

How is a culture of workplace wellness built? Although there are no specific frameworks for building a culture of wellness, the Ateneo CORD's culture-building model describes six components necessary to shape organizational culture. It uses the acronym CREATE that stands for communication of desired values, role modelling of leaders, engagement of employees in culture building, alignment of systems and structures to desired values, training and development, and evaluation and reinforcement of culture-consistent behaviors (Hechanova, Melgar, Falguera, \& Villaverde, 2014). Communication of values involves leaders articulating the values and standards they wish employees to practice. Role modelling refers to how leaders lead by example and provide support for the desired values. Employee engagement describes how leaders engage employees and encourage them to co-create culture building interventions. Alignment of systems and structures refers to ensuring the procedures, policies and infrastructures support the company values. Evaluation and reinforcement refers to mechanisms to measure and reward desired behaviors (Hechanova et al., 2014).

The CREATE model has been used in describing how to build cultures of innovation and integrity (Hechanova et al., 2014) but has not been applied specifically to workplace wellness. However, the components appear to be aligned to the studies on workplace wellness (i.e. Elia \& Rouse, 2016; Dickson-Swift et al., 2014). A study among Australian workplaces reports that supportive managers, respectful personal relationships, flexible work, and good communication are important elements in creating a health-promoting work environment (Dickson-Swift et al., 2014). Another study comparing companies that successfully implemented workplace wellness with those that were less successful reported two critical success factors: engaged management and effective promotion of the programs. The authors also reported that companies with successful workplace wellness initiatives recognized the value of integrating program design with measurement and communication. Given these, they recommended five best practices revolving around leadership, policies and practices, communication, targeted program and evaluation. They emphasized the importance of support from top management and leadership by example. They suggested that existing policies and practices should reflect a culture of health. They identified communication as a critical component to gain understanding and commitment of employees. They also proposed that company programs need to be designed based on an assessment of the health status of employees. Finally, they highlight the importance of benchmarking and evaluating outcomes of interventions (Elia \& Rouse, 2016).

Thus, this study seeks to examine workplace wellness strategies in Philippine organizations using the CREATE framework as a lens. Specifically, we ask, how do organizations ...

a) Communicate the value for workplace wellness?

b) Role model and support workplace wellness?

c) Engage employees in developing, implementing, and participating in workplace wellness initiatives?

d) Align their systems and structures to support workplace wellness?

e) Train employees to enable workplace wellness?

f) Evaluate and reinforce workplace wellness? 


\section{Methodology}

\subsection{Overview}

This study is an exploratory qualitative study consisting of two phases of focus group discussions (FGDs). Data was collected as part of a broader study that aims to create and pilot a workplace wellness program for organizations in the Philippines. In the first phase, open-ended questions were used to validate the presence of the CREATE dimensions with regards to wellness in the workplace. In the second phase, FGDs were used to elicit specific practices under each dimension. Thematic analysis was then used to analyze the data.

\subsection{Participants}

Participants were chosen through non-random sampling. Inclusion was based on their voluntary participation in the aforementioned study to develop a workplace wellness program for organizations. There were 23 participants who volunteered in the first FGD, majority were female ( 21 females and two males). They represented 15 institutions from diverse industries that include manufacturing, mining, utilities, non-profit, marketing and advertising, academe, and government. Participants were mostly heads of the company, Human Resource (HR) practitioners, or in-charge of the wellness initiatives of their institutions. The second FGD had 20 participants (17 females and three males). They represented 13 organizations from different industries including mining, health, manufacturing, utilities, food, academe, construction, marketing and advertising, finance, religious, and government. Participants were mostly HR practitioners, health professionals employed by the organizations, or organization leaders.

\subsection{Data collection}

Focus group discussions were used to gather data. In the first phase, participants were invited to discuss issues regarding workplace wellness. Participants were divided into three smaller groups so as to maximize participation and discussion. Topics included substance use, wellness programs, and barriers towards implementation of wellness programs. The discussions were audio recorded and transcribed. The second FGD was conducted during a training workshop on workplace wellness. Participants were invited to identify and write down the strategies that their companies use in relation to each dimension of the CREATE model. They were then asked to expound on the answers that they had written down with the entire group through a plenary session. For both FGDs, Filipino, English, or a mix of both languages was used, depending on the preference of the participants. For the purpose of this study, sample quotes provided have been translated to English. During the first FGD, participants signed an informed consent form and were assured that they would remain anonymous, thus, identifying information such as their names and the names of their organizations are not included. The study underwent ethical review and was approved by the Ateneo de Manila University Research Ethics Office.

\subsection{Data analysis procedure}

The first FGD was analyzed using thematic analysis. Data from the first phase was used to validate the presence of the CREATE dimensions with regards to wellness practices of organizations. During the second FGD, participants were introduced to the CREATE framework, and they themselves identified strategies under each dimension. The researchers combined the results from both FGDs and clustered together similar responses using deductive thematic analysis, which entails interpreting the data through a particular theoretical lens (Clarke, Braun, \& Hayfield, 2015). In this study, the CREATE framework was used as a guide for coding. In some cases, the responses would fall under multiple headings, in which case, the researchers discussed with each other and consulted with experts in the field to identify where they may be most appropriate.

Following Yardley's (2000) principles for evaluating validity in qualitative research, the following were considered throughout the study: (1) sensitivity to context, (2) commitment and rigor, (3) coherency and 
transparency, and (4) impact and importance. Sensitivity to context was demonstrated by understanding the background of the participants (i.e. as HR practitioners and leaders of organizations) and the cultural and political contexts. Particularly, the general Filipino culture and the current focus on substance use by the present political administration were considered. For commitment and rigor, participants were given opportunities to elaborate on their answers, and to engage with each other to deepen the discussion. Furthermore, participants represented different industries and types of organizations, and this provided a broader perspective on the topic. For transparency, the researchers reflected on their reflexivity as psychologists who are both involved in the teaching and practice of industrial organizational psychology. This means that while the researchers had to be careful not to let their own knowledge and experiences influence the answers of the participants, their background also allowed them to speak the language of the participants and facilitate the discussions more effectively. With regards to coherence, the fit of the methods and frameworks to the research questions were considered and deemed to be adequate in providing relevant data. Finally, impact and importance of the research were addressed by identifying useful and practical implications for organizations and their workforce.

\section{Results}

All participants were able to share wellness strategies from their organizations that could be categorized using the CREATE framework. Table 1 summarizes the key strategies for each of the dimensions, together with some actual quotations form the participants to further illustrate. The responses covered a variety of initiatives that include programs, activities, systems, considerations, policies, and the involvement of different stakeholders.

\section{Table 1}

Summary of wellness strategies

\begin{tabular}{|c|c|c|}
\hline $\begin{array}{c}\text { Dimensions of } \\
\text { CREATE framework }\end{array}$ & Strategies & Sample Quotes \\
\hline $\begin{array}{l}\text { Communicate the value of } \\
\text { wellness }\end{array}$ & $\begin{array}{l}\text { Share the importance of total } \\
\text { wellness } \\
>\quad \text { Utilize key figures (e.g. leaders or } \\
\text { famous individuals) to deliver } \\
\text { messages } \\
>\quad \text { Use a variety of media (e.g. printed, } \\
\text { electronic, face to face discussions) } \\
>\text { Consider the timing of } \\
\text { communication } \\
>\text { Keep communication lines with } \\
\text { employees open }\end{array}$ & $\begin{array}{l}\text { "We have the bulletin board with health and benefits issues } \\
\text { that we update every now and then." } \\
\text { "We invite doctors that talk about a particular illness." } \\
\text { "When we send tips on nutrition or diseases via email, it's } \\
\text { nicer to send infographics instead of written text that is boring, } \\
\text { because they don't read that. They prefer drawings and } \\
\text { images." } \\
\text { "More than the 'how' to communicate, it's what to } \\
\text { communicate...We communicate total wellness, not just } \\
\text { physical." }\end{array}$ \\
\hline Role modelling & $\begin{array}{l}>\text { Managers and administrators take } \\
\text { ownership of programs } \\
>\quad \text { Leaders participate in activities } \\
>\text { Leaders model healthy behaviors } \\
>\text { Tap informal leaders such as health } \\
\text { champions among the employees }\end{array}$ & $\begin{array}{l}\text { "Since we are the ones who spearheaded the establishment of } \\
\text { the wellness program, it is embarrassing if we ourselves aren't } \\
\text { healthy. So little by little we engage ourselves in a lot of } \\
\text { wellness and fitness activities." } \\
\text { "Last year there were five who were champions, who reached } \\
\text { their health goals. They set good examples to employees and } \\
\text { we send their pictures through email to encourage other } \\
\text { employees." }\end{array}$ \\
\hline Engage employees & $\begin{array}{l}>\text { Gather feedback on the health status } \\
\text { and wellness needs of employees } \\
\text { through surveys } \\
>\quad \text { Form wellness committees among } \\
\text { the employees } \\
>\text { Offer wellness classes and sports } \\
\text { activities } \\
>\text { Have contests related to wellness } \\
>\text { Promote camaraderie and relaxation } \\
\text { through team-building and bonding } \\
\text { sessions } \\
>\text { Inquire about the wellbeing of } \\
\text { employees through chats and } \\
\text { counselling } \\
\text { Empower teams to address their } \\
\text { stressors }\end{array}$ & $\begin{array}{l}\text { "It's like a needs assessment... It's important to know what } \\
\text { they think they need to be well... So that when you provide the } \\
\text { service, it matches what they believe they need." } \\
\text { "Because we don't want employees to see wellness as just an } \\
\text { HR program, we created an employee activities committee } \\
\text { where each department is represented. They will be the one to } \\
\text { plan and execute. They just need to submit to HR for approval. } \\
\text { We want to engage all of them." } \\
\text { "Some people like myself will visit an office and just ask how } \\
\text { they are. I don't have an agenda, just asking how they are and } \\
\text { sometimes that's when they share about their problems." } \\
\text { "We have a fitness gym, and every day, Zumba classes are } \\
\text { offered." }\end{array}$ \\
\hline
\end{tabular}


Table 1 ... continued

\begin{tabular}{|c|c|c|}
\hline $\begin{array}{c}\text { Dimensions of } \\
\text { CREATE framework }\end{array}$ & Strategies & Sample Quotes \\
\hline $\begin{array}{l}\text { Align systems and } \\
\text { structures }\end{array}$ & 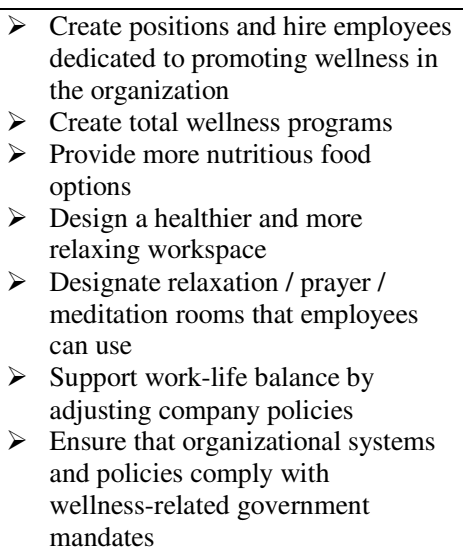 & $\begin{array}{l}\text { "We have a psychiatrist and doctors within the compound." } \\
\text { "There is a food vendor who sells there and we discourage her } \\
\text { from selling junk food." } \\
\text { "They undergo rehabilitation so we comply with DOLE } \\
\text { (Department of Labor and Employment) guidelines." } \\
\text { "People had to travel, they give up a Sunday, a very precious } \\
\text { weekend because they have to be somewhere else on a } \\
\text { Monday for training. So it may sound ordinary, but all our } \\
\text { trainings now start Tuesdays. Because we believe that you } \\
\text { have a right to your family life, and travel time can now } \\
\text { happen on Monday instead of Sundays." } \\
\text { "There is a specific area designed for employees who really } \\
\text { feel stressed. Anytime during the day, they can just go there. } \\
\text { There is aromatherapy, soothing music, we can play } \\
\text { mindfulness videos, and there are inspirational books." }\end{array}$ \\
\hline Training and development & $\begin{array}{l}\text { Include wellness in the required } \\
\text { training for employees } \\
\text { Offer training for a variety of } \\
\text { wellness-related topics } \\
>\text { Support spiritual development } \\
\text { through retreats } \\
>\quad \text { Tailor fit wellness trainings for } \\
\text { specific groups or positions in the } \\
\text { company }\end{array}$ & $\begin{array}{l}>\text { "We have lectures to understand how to control and prevent } \\
\text { diseases." } \\
\text { "It's a program that teaches [a particular position] financial } \\
\text { wellness, spiritual wellness, all aspects of wellness." } \\
>\text { "But one thing that is valued here in the university is really } \\
\text { spiritual wellness. So for our employees, they're allowed to do } \\
\text { 3-day retreats, 5-day retreats that are paid for by the university. } \\
\text { Even 30-day retreats for those who can last that long." } \\
>\text { "Wellness classes are fully paid for by the company." }\end{array}$ \\
\hline Evaluate and reinforce & 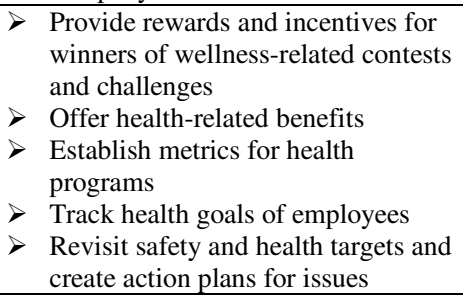 & $\begin{array}{l}\text { "Every after APE (Annual Physical Exam), we have individual } \\
\text { health goals where the APE results are discussed. We have } \\
\text { one-on-one consultations, and from there we come up with } \\
\text { their goals. For short-term, after three months, they return to us } \\
\text { to see if they reached their goal. Similarly, after six months to } \\
\text { one year, they return to us for re-evaluation." } \\
\text { "How do you make sure this happens? We have a monthly } \\
\text { review and weekly review to see if you achieved the } \\
\text { operational targets." }\end{array}$ \\
\hline
\end{tabular}

\subsection{Communicate the value of wellness}

Company representatives shared that their organizations explicitly stated the importance of total wellness that they defined to include physical, spiritual, mental, and emotional wellness. Another company also reported that they highlight the relationship of wellness with productivity to drive its importance.

Although communication of the value of wellness was done in a number of ways, a commonly cited mechanism was through role modeling of leaders. For example, one institution shared that they orient and engage leaders in implementing wellness initiatives so they can champion these to their subordinates. Beyond engaging organization leaders in communicating the value of wellness, organizations reported a variety of other media. Some utilized printed or physical materials, such as bulletin boards, brochures, fliers, and the company newsletter. Others relied on electronic means for communicating about wellness, such as email and social media (Facebook). Participants also shared that they use infographics and images instead of just plain text in order to make the information more interesting for employees. Face-to-face communication was also utilized because, as one participant shared, "employees tend to automatically delete generic emails." Other mechanisms such as brownbag meetings, wellness circles, and lectures by professionals were also used. Events such as wellness fairs where exhibitors are provided free space and allowed to distribute samples or provide services were another means to highlight the importance of health to employees. A marketing company reported using famous exercise instructors and artists to encourage employees to join wellness programs.

In terms of the timing of communication, one company reported that their health programs and strategies are included in the on-boarding program of all new employees. Non-working hours such as lunchtime were also utilized for brownbag meetings. 
Beyond merely disseminating information, one company mentioned the importance of empowering employees to speak up about their personal needs and concerns. Supervisors are encouraged to keep communication lines open so that employee needs are heard and addressed promptly.

\subsection{Role modelling}

Although many companies reported that their wellness initiatives were managed by HR staff, organization leaders were active participants and champions of wellness programs. For example, one participant mentioned that their managers are the "owners" of their workplace ergonomics initiative. Another participant reported that their leaders participate in the various health programs of the company, such as the sports activities and dance exercises. Top-level managers are tapped as "influencers" for the wellness initiatives of the company. Another representative reported that their leaders model healthy eating practices such as drinking water instead of soda. Another institution mentioned that their administrators are the "prime movers" of their company's bike to work program.

Beyond tapping formal leaders, some companies also tapped informal leaders to serve as champions and models for other employees. One company shared that they have safety marshals for every floor and department. Another company reported that their employees created individual health goals based on the results of their annual physical exams and employees who are able to reach their health goals were tapped as champions. The company disseminated their achievements and pictures to encourage other employees to participate.

\subsection{Engage employees}

With regards to engagement, some organizations used anonymous surveys in order to gather feedback from employees on their health status and wellness needs. This assessment of needs informed the organization on what particular strategies to pursue. Another organization mentioned having an employee activities committee where each department is represented. The committee planned activities and programs to engage employees, submitted these plans to HR for approval, and then executed the programs.

Activities to improve physical health were the most commonly mentioned health intervention. Many Filipino companies engage employees through regular wellness classes such as zumba, yoga, dance and boxing, which are offered for free. After-work sports activities are also available. Occasional activities such as fun runs, family days, and annual sportsfests were also highlighted. Another institution reported using local games in the annual sportsfest.

To elicit greater participation, some companies harness the employees' sense of competition through contests. Examples of these include weight loss contests and slogan-making contests for wellness programs. Winners are given prizes and awards.

Opportunities to build camaraderie among co-workers while simultaneously promoting relaxation were also utilized. One company shared how their company subsidizes a monthly bonding session for employees called "kwentuhan", which in Filipino means "sharing stories". Participants from other companies also report having teambuilding activities and outings to promote better relationships among employees and decrease stress. Employees are also invited to bond with each other and relieve stress through movie nights or dinners.

Employees are also engaged through chats and counselling. One organization reported that nurses and HR personnel hold "kumustahan"1 sessions with employees. These sessions are thus used to inquire about the wellbeing of employees. They involve casual and friendly conversations as opposed to structured feedback sessions or meetings. According to the participant, counselling is provided if the employee needs help with certain issues or problems. A company reported having a Facebook group for employees to engage with each

1 “Kumustahan" stems from a Filipino word used to ask "how are you?". 
other on non-work matters such extra-curricular activities and health.

Beyond engaging employees to participate, other companies empower teams. In one company, team members come together to understand their personal and team stressors. The team then plans on what to do to mitigate stress for their work group.

\subsection{Align systems and structures}

In some organizations, positions are created that are dedicated towards to improving wellness in the organization. In a multinational company, health and wellness is a global directive and there is a full-time manager within the HR department responsible for this. Other companies mentioned having health professionals available for the health needs of employees, such as nurses and psychiatrists.

Some companies created nutrition and wellness programs for employees, and allocated resources for these activities and health programs. One company's total wellness program - encompassing mind, body and spirit was actually recognized as a "program of the year" by a national association for people management. In another company, the health and wellness programs are part of their program of health and safety. Another participant reported that the Department of Health targets are included in the operational master plan of the company.

With regards to nutrition, a participant from a company reported removing junk food from their pantry. Another company prohibited its vendors from selling junk food, and required them to have healthier options.

Physical structures and the design of workspaces were also taken into consideration. One company sought to create a more conducive environment by making their office more "homey", by using sofas, beanbags and a swing. Greenery was incorporated into their workspace. For other organizations, specific rooms were designated as lounges, prayer rooms or meditation areas that are available for use when employees need to de-stress during the day. One company provided massage chairs, wellness books, musical instruments that employees could use anytime. Another representative shared that they provided a calming room with soothing music, mindfulness videos, and aromatherapy. Some companies also had sports wellness centers furnished with gym equipment.

Work-life balance was enforced through company policies. One participant shared that they adjusted the schedules of trainings and work-related out-of-town trips. Instead of starting on Mondays, company trainings start on Tuesdays to ensure that Sundays (which is usually when employees go to church and spend time with family) are not used for work-related travel. Another policy to ensure wellness was the discouragement of over-time (OT) to allow employees to safeguard their personal time.

Beyond alignment of internal systems, structures and policies, companies also sought to comply with government mandates on wellness. For example, in relation to substance use, participants mentioned that they conducted random drug testing in accordance with government guidelines. Disciplinary measures as well as rehabilitation options were also put in place. If employees tested positive for drug use, they were required to undergo rehabilitation with the cost of treatment sometimes funded by the organization. Disciplinary actions such as memos, suspension or termination were also put in place. In compliance with government regulations on smoking, companies reported banning smoking inside the office.

\subsection{Training and development}

Some participants shared that attendance to wellness-related topics and activities are included in the required training hours for employees. Companies reported a variety of wellness-related training topics ranging from personal health, stress management, ergonomics, nutrition, calorie counting, sleep, and proper exercise. Topics are sometimes patterned after the Department of Health calendar (i.e. prevention and control of common diseases and illnesses such as bird flu and rainy season illnesses). One company reported training their canteen concessionaires on cooking so that food options are healthier for employees. 
Training for particular sports is also available, with equipment provided for by the company. Team-based trainings and sessions are also utilized. Participants also mentioned having trainings designed for a specific group or position in the company.

Training and development initiatives go beyond physical and psychological health. One company reported conducting financial independence training because financial problems were a source of stress for many of their employees. Spiritual well-being was mentioned by a number of organizations. Many organizations reported sponsoring masses or prayer time in the office. A university offers retreats ranging from three to even up to 30 days to employees as a means of promoting spiritual well-being. Employees were allowed to take time off from work in order to participate, and costs were covered by the organization.

\subsection{Evaluate and reinforce}

To reinforce the wellness and encourage participation from employees, incentives and prizes such as trophies, medals and gift certificates were provided by the company for competition winners. Awards were given not just to individual employees, but also to groups or teams. One company mentioned they awarded the healthiest worksite, based on their compliance on health care assessments, attendance in required training, and decrease in the number of incidents and injuries. Healthy behavior was also encouraged outside the office by incorporating health-related benefits such free or discounted membership to fitness centers.

With regards to evaluation, a company reported establishing metrics for success for their health programs, based on the results of the annual physical exams of employees. Individual health goals are revisited after three months (short-term) and 6-12 months (long-term) and employees who are able to meet their goals are recognized. In another company, compliance is measured and health targets are revisited during the weekly or monthly operations reviews. Statistics regarding first aid and injuries, abnormal findings, top illnesses, clinic visits, health claims, and overtime hours are noted and included in the points-for-discussion. If there are issues with regards to health targets, action plans must be written for how to remedy them. Results have implications on the performance rewards per month.

\section{Discussion}

Findings show a myriad of strategies that Philippine companies use to ensure workplace wellness. Depending on the resources available, strategies ranged from costly (i.e. creating infrastructure or architecture that promotes wellness) to practically no cost at all (i.e. adjusting training days so that employees' weekends are not affected). To minimize costs, companies utilized existing resources from the national government or public sites. This was most common among small companies who had limited resources for wellness.

All of the strategies shared by the participants could be categorized using the dimensions of the CREATE model. However, among the various CREATE dimensions in the framework, there appeared to be fewer companies that identified strategies related to evaluation and reinforcement. Those who reported these were larger organizations. This is consistent with findings of Sabharwal et al. (2016) that less than half of US cities in their sample conducted formal evaluations of their wellness programs. This suggests that evaluation is one area that organizations may need more capability, especially given its importance for program success (Sabharwal et al., 2016).

Many of the strategies identified were related to physical health, such as exercise, sports competitions, awareness about illnesses and nutrition, and medical check-ups. This suggests that these types of wellness initiatives are top-of-mind for companies and may be easier to execute. However, a number of participants reported that encouraging wellness went beyond the physical, but also involved the psychological, social, and spiritual dimensions. Examples of these include strategies to reduce stress, maintain work-life balance, promote harmonious relationships among co-workers, and taking time to talk to or have counselling sessions with employees. Indeed, a holistic view of wellness can be adopted, with some participants mentioning "total 
wellness" as what their company strives for.

\subsection{Context and culture of wellness}

Majority of the strategies used in Philippine organizations are not unique to those used by companies across the globe. However, the results also suggest some approaches are context-specific and culturally nuanced. For example, socio-political factors appeared to influence companies' focus on wellness. In the Philippines, the current administration has put a lot of focus on substance use. Thus, companies are mandated to comply with policies and guidelines with regards to drug testing and smoking. These laws pushed companies to change their own policies and required them to put in place substance use interventions.

The results also highlighted the important role of leaders in communicating, role modelling and engaging employees. This finding is understandable given literature that the Philippines scores highly on power distance, suggesting that Filipino workers tend to defer to authority and view their superiors as inaccessible (Hofstede, 2003). This suggests that creating a culture of wellness involves not just the implementation of health-related programs or activities by HR, but by engaging and training leaders to be role models and champions.

Indicative of a high power distance culture, Philippine organizations also focused on empowering employees to assert their needs and concerns. Some organizations did this by utilizing action-research whereas others used team building as venues for groups to identify their stressors and plan for initiatives. The use of leaders and groups are important strategies because studies show that Filipinos are generally hesitant to open up to mental health professionals because they are generally shy about sharing personal matters to strangers, fear that seeing mental health professionals means they are crazy, or do not wish to damage the reputation of their family (Hechanova \& Waelde, 2017). Thus, they prefer to seek help from family and friends (Hechanova \& Waelde, 2017). Given this, there may be a need for organizations to lessen the stigma of seeking professional help as well as build the capability of leaders to counsel their employees.

Conversely, the results suggest that many Philippine organizations utilize groups in the diagnosis, and planning and implementing of interventions. The use of groups is understandable given the collectivist culture of Filipinos. In such cultures, individuals are interdependent with kin, community, and society (Hofstede, 2003). Studies on Filipino disaster survivors reveal that they tend to identify external sources of strength (faith in God, family, friends) rather than internal or personal attributes (Hechanova \& Waelde, 2017). Engelbrecht and Jobson (2016) suggested that in collectivist cultures, group therapies increase empowerment and reduce psychological shame, isolation, and helplessness. A study among Filipino disaster survivors suggests that interventions that focus on individual maladjustment or stress reactions may not be as relevant as programs that encourage social support and interdependent coping efforts (Hechanova, Ramos \& Waelde, 2015).

Given the interdependent nature of Filipinos, wellness may not be an individual construct. This is reinforced by a study of Filipino workers' motivation suggesting that in contrast to Maslow's hierarchy of needs that emphasizes self-actualization, Filipino workers are primarily motivated by the actualization of their family members. Thus, they work not for themselves, but in order to enable the actualization of their family members (Ilagan, Hechanova, Co, \& Pleyto, 2014). Thus, employee stress may actually emanate from work-life issues and family obligations.

The value for family and friends is also reflected in how some respondents reported that their companies seek to build spaces that resemble living rooms. Some companies also utilized informal chats and getting-to-know-you sessions that reflect the importance of going beyond professional relationships. Group-based interventions and activities were also emphasized. This finding is consistent with literature that in interdependent and family-oriented cultures, bosses are more like parents, colleagues are friends and work teams are second families (Hechanova \& Franco, 2012).

A handful of participants reported that in their company, wellness and health also included spirituality. 
Retreats and prayer rooms were identified as strategies to promote wellness. This is understandable given that the Philippines is a country where majority (90\%) of the populace are Catholics and/or Christians. A study reports that seeking spiritual support is a common coping mechanism of Filipinos (Hechanova \& Waelde, 2017). Nakonz and Shik (2009) suggested that religion influences the Filipino's resilience in a number of ways by helping them reappraise or redefine their problems. Christians see hardships as spiritual opportunities, believing that "God never gives you a problem you cannot manage". Prayer is a key coping strategy and is reinforced by the belief that "God helps those who help themselves." Finally, surrendering their difficulties to God and praying for the capacity to deal with the situation is another common coping mechanism of Christians (Nakonz \& Shik, 2009). Furthermore, Church masses, prayer groups, ministries, and religious communities are important social capital. Religious groups provide instrumental support such as helping out members in financial distress (Nakonz \& Shik, 2009).

\subsection{Implications}

Rather than creating and running separate programs and initiatives, HR practitioners can seek to build a culture of wellness in their organizations that addresses holistic health. The CREATE framework can be utilized as a guide to ensure that the strategies build on each other and are coherent. Context, such as cultural values and socio-political issues, must be taken into account in order for wellness strategies to be relevant to the employees and effective in improving health. Finally, the importance of program evaluation should be highlighted by HR practitioners. Despite requiring additional resources and time, evaluation allows for improvements to be made in the company's wellness strategies as well as the documentation of results to assess efficacy.

For researchers, teachers, and learners in health and psychology, this study has implications on the way workplace wellness is taught and understood. Results show that holistic workplace wellness extends beyond medical and psychological issues. Moreover, wellness can be viewed from a lens of culture-building, which involve not just program creation but also the analysis of supporting organizational structures, policies, HR systems and communication strategies.

\subsection{Limitations and future research}

This exploratory study on building a culture of wellness utilized qualitative data from FGDs. One limitation of the study was that convenience sampling was used and as such, it provides information on the various approaches used but not their prevalence. Quantitative methodologies can be used to establish prevalence as well as link wellness programs with employee outcomes such as health, quality of life, engagement, etc. In addition, future studies can examine wellness strategies in the context of particular variables such as size and type of the organization and industry.

\section{Conclusion}

The study emphasizes the value of taking a holistic and contextualized approach to building a culture of wellness in the workplace. It utilized the CREATE framework to better understand the strategies that companies in a developing country use in order to promote wellness in their organization. Findings suggest that a myriad of strategies are available. However, culture and context should be considered when planning strategies to implement. Given the importance of wellness for individuals and for organizations, it is crucial that strategies be integrated and that an overall workplace culture is created. The study highlighted cultural nuances such as stigma towards help seeking, high power distance and collectivism that are important to consider in designing interventions.

Acknowledgements: The authors would like to acknowledge the Ateneo de Manila University Research Council Grants for funding this study. 


\section{References}

Akanji, B. O. (2016). A case study on occupational stressors and effective stress management interventions from a call center perspective. International Journal of Research Studies in Psychology, 5(2), 13-24. https://doi.org/10.5861/ijrsm.2016.1394

Bazarko, D., Cate, R., Azocar, F., \& Kreitzer, M. (2013). The impact of an innovative mindfulness-based stress reduction program on the health and well-being of nurses employed in a corporate setting. Journal of Workplace Behavioral Health, 28(2), 107-133. https://doi.org/10.1080/15555240.2013.779518

Clarke, V., Braun, V., \& Hayfield, N. (2015). Thematic analysis. In J.A. Smith (Ed.), Qualitative Psychology: A practical guide to research methods (3rd ed., pp. 222-248). London: Sage.

Dickson-Swift, V., Fox, C., Marshall, K., Welch, N., \& Willis, J. (2014). What really improves employee health and wellbeing. Findings from regional Australian workplaces. International Journal of Workplace Health Management, 7(3), 138-155. https://doi.org/10.1108/IJWHM-10-2012-0026

Elia, J., \& Rouse, M. (2016). Do workplace wellness programs work? Plans and Trusts, Sept/Oct, 12-17.

Engelbrecht, A., \& Jobson, L. (2016). Exploring trauma associated appraisals in trauma survivors from collectivist cultures. SpringerPlus, 5(1), 1-11. https://doi.org/10.1186/s40064-016-3043-2

Hofstede, G. (2003). Culture's consequences: Comparing values, behaviors, institutions and organizations across nations. Thousand Oaks, CA: Sage Publications.

Hechanova, M. R., \& Franco, E. P. (Eds). (2012). Rebirth and reinvention: Transforming Philippine organizations. Quezon City, Philippines: Ateneo de Manila University Press.

Hechanova, M. R., Melgar, I., Falguera, P., \& Villaverde, M. (2014). Organisational culture and workplace corruption in government hospitals. Journal of Pacific Rim Psychology, 8(2), 62-70. https://doi.org/10.1017/prp.2014.5

Hechanova, M. R. M., Ramos, P. A. P., \& Waelde, L. C. (2015). Group-based mindfulness-informed psychological first aid after Typhoon Haiyan. Disaster Prevention and Management, 24, 610-618. https://doi.org/10.1108/DPM-01-2015-0015

Hechanova M. R., Waelde, L. C., Docena, P., Alampay, L. P., Alianan, A., Flores, J., . . Melgar, I. (2015). The development of Katatagan: A resilience intervention for Filipino disaster survivors. Philippine Journal of Psychology, 48(2), 105-131.

Hechanova, M. R., \& Waelde, L. (2017). The influence of culture on disaster mental health and psychosocial support interventions in Southeast Asia. Mental Health, Religion \& Culture, 20(1), 31-44. https://doi.org/10.1080/13674676.2017.1322048

Ilagan, J. R., Hechanova, M. R., Co, T. A., \& Pleyto, V. J. (2014). “Bakit ka kumakayod?” Developing a Filipino needs theory of motivation. Philippine Journal of Psychology, 47(1), 117-143.

Kanene, K., \& Mushungekelwa, M. D. (2016). Sources of stress experienced by secondary school teachers in Choma District Southern Province of Zambia. International Journal of Research Studies in Psychology, 5(4), 89-102. https://doi.org/10.5861/ijrsp.2016.1609

Largo-Wight, E., Wlyudka, P., Merten, J., \& Cuvelier, E. (2017). Effectiveness and feasibility of a 10-minute employee stress intervention: Outdoor booster break. Journal of Workplace Behavioral Health, 32(3), 159-171. https://doi.org/10.1080/15555240.2017.1335211

Lee, S., Blake, H., \& Lloyd, S. (2010). The price is right: Making workplace wellness financially sustainable. International Journal of Workplace Health Management, 3(1), 58-69. https://doi.org/10.1108/17538351011031948

McPeck, W., Ryan, M., \& Chapman, L. S. (2009). Bringing wellness to the small employer. American Journal of Health Promotion, 23(5), 1-10. https://doi.org/10.4278/ajhp.23.5.tahp

Meng, L., Wolff, M. B., Mattick, K. A., DeJoy, D. M., Wilson, M. G., \& Smith, M. L. (2017). Strategies for worksite health interventions to employees with elevated risk of chronic diseases. Safety and Health at Work, 8(2), 117-129. http://doi.org/10.1016/j.shaw.2016.11.004

Nakonz, J., \& Shik, A. W. Y. (2009). And all your problems are gone: Religious coping strategies among Philippine migrant workers in Hong Kong. Mental Health, Religion \& Culture, 12(1), 25-38. 
Building a culture of workplace wellness: Perspectives from Philippine organizations

https://doi.org/10.1080/13674670802105252

Patterson, P. D., Smith, K. J., \& Hostler, D. (2016). Cost-effectiveness of workplace wellness to prevent cardiovascular events among US firefighers. BMC Cardiovascular Disorders, 16(229), 1-7. http://doi.org/10.1186/s12872-016-0414-0

Pidd, K., Roche, A., \& Fischer, J. (2015). A recipe for good mental health: A pilot randomized controlled trial of a psychological wellbeing and substance use intervention targeting young chefs. Drug Education Prevention Policy, 22(4), 352-361. https://doi.org/10.3109/09687637.2015.1016400

Riley, K., Park, C., Wilson, A., Sabo, A., Antoni, M., Braun, T., . . Cope, S. (2016). Improving physical and mental health in frontline mental health care providers: Yoga-based stress management versus cognitive behavioural stress management. Journal of Workplace Behavioral Health, 32(1), 26-48.

https://doi.org/10.1080/15555240.2016.1261254

Rucker, M. (2017). Workplace wellness strategies for small businesses. International Journal of Workplace Health Management, 10(1), 55-68. https://doi.org/10.1108/IJWHM-07-2016-0054

Sabharwal, M., Kiel, L. D., \& Hijal-Moghrabi, I. (2016). Best practices in local government wellness programs: the benefits of organizational investment and performance monitoring. Review of Public Personnel Administration, 1-22. https://doi.org/10.1177/0734371X16682817

Safaria, T. (2014). Efficacy of indigenous imagery breathing-relaxation training through Javanese Gamelan music to reduce job stress responses among teachers at special-needs school. International Journal of Research Studies in Psychology, 3(5), 49-61. https://doi.org/10.5861/ijrsp.2014.904

Schulte, B., O’Donnell, A., Kastner, S., Schidt, C., Schafer, I., \& Rimer, J. (2014). Alcohol screening and brief interventions in workplace settings and social services: A comparison of the literature. Frontiers in Psychiatry, 5(131), 1-9. https://doi.org/10.3389/fpsyt.2014.00131

Sureweera, I. K., Wijesinghe, S. D., Senanayake, S. J., Herath, H. D., \& Jayalal, T. A. (2016). Occupational health issues in small-scale industries in Sri Lanka: An under-reported burden. Work, 55, 263-269. https://doi.org/10.3233/WOR-162397

World Health Organization. (2007). WHO-AIMS Report on mental health system in the Philippines. Retrieved from http://www.who.int/mental_health/evidence/philippines_who_aims_report.pdf

World Health Organization. (2013). WHO Global plan of action on workers' health (2008-2017): Baseline for implementation. Retrieved from http://www.who.int/occupational_health/who_workers_health_web.pdf

Yardley, L. (2000). Dilemmas in qualitative health research. Psychology and Health, 15(2), 215-228. https://doi.org/10.1080/08870440008400302 
Hechanova, M. R. M., \& Caringal-Go, J. F. A. 